EPiC Series in Computing
Volume 52, 2018, Pages 68-81
$\begin{aligned} & \text { ICT4S2018. 5th International Conference on Informa- } \\ & \text { tion and Communication Technology for Sustainability }\end{aligned}$

\title{
Indirect Effects of the Digital Transformation on Environmental Sustainability: Methodological Challenges in Assessing the Greenhouse Gas Abatement Potential of ICT
}

\author{
Jan C. T. Bieser ${ }^{1}$ and Lorenz M. Hilty ${ }^{1,2}$ \\ ${ }^{1}$ Department of Informatics, University of Zurich, Zurich, Switzerland \\ ${ }^{2}$ Empa, Swiss Federal Laboratories for Materials Science and Technology, St. Gallen, Switzerland \\ jan.bieser@ifi.uzh.ch, hilty@ifi.uzh.ch
}

\begin{abstract}
The digital transformation has direct and indirect effects on greenhouse gas (GHG) emissions. Direct effects are caused by the production, use and disposal of information and communication technology (ICT) hardware. Indirect effects include the changes to patterns of production and consumption in other domains. Studies quantifying both effects often conclude that net effects (indirect minus direct effects) can lead to a significant GHG emission reduction. We revisited a study by Accenture on ICT's GHG abatement potential in Switzerland by reassessing the main assumptions. Our results confirm that ICT has the potential to reduce GHG emissions in Switzerland, especially in the building, transport and energy domains. However, our results also suggest that the potential is smaller than anticipated and that exploiting this potential requires targeted action. Reasons for differences among these results (and the results of similar other studies) are: degrees of freedom in the assessment methodology, selection of ICT use cases, allocation of impacts to ICT, definition of the baseline, estimation of the environmental impact, prediction of the future adoption of use cases, estimation of rebound effects, interaction among use cases, and extrapolation from use case to societywide impacts. We suggest addressing these methodological challenges to improve comparability of results.
\end{abstract}

Index Terms - Information and communication technology, digitalization, climate change, greenhouse gas emissions, GHG abatement potential, environmental impact assessment. 


\section{Introduction}

In September 2015, the United Nations adopted the Sustainable Development Goals, consisting of 17 goals to "end poverty, protect the planet, and ensure prosperity for all" [1, p. 1]. As of October 2017, 195 member states have become party to the Paris Agreement, which "aims to strengthen the global response to the threat of climate change" and to hold "the increase in the global average temperature to well below $2{ }^{\circ} \mathrm{C}$ above pre-industrial levels" [2, p. 2]. The current Swiss climate target aims at cutting domestic greenhouse gas (GHG) emissions by 30\% from 1990 to 2030.

The development of digital electronics has led to a convergence of technologies to store, transmit and process information, a process with far-reaching consequences [3]. In recent years, "many and diverse domains of social life" increasingly structure "around digital communication and media infrastructures", a process called "digitalization" [4, p. 1]. Digitalization impacts GHG emissions in two ways: On the one side, an increasing amount of ICT hardware is produced, powered with electricity while being used, and finally disposed of - a system of processes which requires resources and causes emissions to the environment (direct effects). On the other side, ICT has influence on patterns of production and consumption, with manifold consequences (indirect effects). For example, ICT allows us to work from home and have virtual meetings, thus avoiding travel-related GHG emissions. In recent years, many studies have been conducted to quantify both direct and indirect effects. These studies usually conclude that indirect effects are positive (i.e., reducing GHG emissions) and clearly larger than direct effects. The conclusion is that net effects (indirect effects minus direct effects) can lead to a significant total reduction on GHG emissions [5], [6]. For example, the Global e-Sustainability Initiative (GeSI), the ICT industry's association for sustainability, claims that, on a global scale, ICT applications could avoid up to $20 \%$ of annual GHG emissions in 2030 (indirect effect), while the ICT sector cause roughly $2 \%$ of global GHG emissions (direct effect) [6].

Following such claims, the ICT for Sustainability (ICT4S) community and the ICT sector increased their attention to the assessment of indirect effects of ICT on GHG emissions. Telecommunication network operators (TNOs) started estimating the indirect impact of their products and services on GHG emissions. For example, British Telecom (BT) estimated that, by 2020, their customers could avoid three times more GHG emissions by using BT products and services than BT causes itself. Emission avoidance would mainly occur through substitution effects, e.g., by reducing travel emissions through telepresence technologies [7]. Swisscom estimated a factor of two by 2020 [8] and AT\&T a factor of ten by 2025 [9].

A System Dynamics model developed in a project commissioned by the IPTS ${ }^{1}$ of the European Commission on "The Future impact of ICT on environmental sustainability" in the EU yielded a different net effect of ICT on GHG emissions. The simulation results, recently validated with new data [10], suggest that by 2020, positive and negative effects of ICT on GHG emissions tend to cancel each other out across application domains. The authors conclude that a set of policies is necessary to specifically unfold the positive potential of ICT while inhibiting negative effects [11]. The diverging results can be explained by a difference in approaches: The IPTS study was based on a dynamic socio-economic model, whereas the newer studies tried to assess the potentials using a simple static approach. Such inconsistencies in methodological approaches make it difficult for decision makers to correctly interpret the results and take into account the climate change impact in ICT investment or policy decisions.

We will take a closer look at methodological challenges using the case of Switzerland as an example. We will first estimate the indirect impact of ICT on climate change in Switzerland, reconsidering ten ICT use cases previously treated in a study conducted by Accenture Strategy [12] as a Switzerlandspecific follow-up of the SMARTer 2030 study [6]. In our context, the indirect effects are the changes to the GHG emissions (measured in $\mathrm{CO}_{2}$-equivalents $-\mathrm{CO}_{2} \mathrm{e}$ ) caused in other sectors (such as the transport sector or the energy sector) by applying ICT in those sectors. Our study was conducted as a project commissioned by WWF Switzerland and Swisscom [3].

\footnotetext{
${ }^{1}$ Institute for Prospective Technological Studies of the European Commission
} 
Based on the experiences gained in this study, we will then discuss the methodological challenges in the assessment of indirect effects of ICT on GHG emissions. Different ways of dealing with these challenges explain the variation in the results of studies using this type of impact assessment.

\section{Related Work}

Existing studies assessing indirect environmental effects of ICT on GHG emissions either focus on individual ICT use cases or estimate the overarching indirect effect of ICT on GHG emissions. Assessments of individual ICT use cases include, e.g., the comparison of GHG emissions associated with printed books and e-books [13], virtual mobility and physical mobility in a multi-site conference setting [14], as well as traditional music delivery methods using physical CDs and digital music downloads [15].

For the purpose pursued in this paper, we reviewed existing studies assessing the overarching indirect environmental effect of ICT and provide an overview of the most relevant work. The system investigated in such studies is usually defined by geographic boundaries or by the products of an ICT company. These studies use various assessment methods to analyze a set of ICT application domains (such as transport) relevant in the system under study and a portfolio of use cases (such as "car sharing") for each domain.

The project "The future impact of ICT on environmental sustainability" [11] estimated the direct and indirect environmental effects of ICT in the European Union. It was based on a System Dynamics model to analyze the impact of ICT production, use and disposal on the energy, transport, goods, services and waste domains and how these impacts affect total energy consumption and GHG emissions (among other environmental indicators). By simulating the development from 2000 to 2020, the authors found that the increasing and decreasing effects of ICT on total energy consumption and the resulting GHG emissions will roughly cancel each other out. Only by selectively promoting use cases with high abatement potential (such as intelligent heating) and inhibiting undesirable effects (such as rebound effects in transport), an overall reduction of GHG emissions would be possible. In 2014, the model was re-validated with updated empirical data, which qualitatively confirmed the results of the original study [10].

The World Wide Fund for Nature (WWF) conducted several studies to identify and measure the potential for ICT-enabled GHG emission reduction. The studies qualitatively and quantitatively explore the direct and indirect environmental impact of ICT in the EU and on a global scale [5], [16]. For example, WWF estimated the GHG reduction potential in the EU through flexi-work, audio and video conferencing, online phone-bills, virtual answering machine and web-based tax return to be $48.37 \mathrm{Mt}$ $\mathrm{CO}_{2}$ compared to $4.73 \mathrm{Mt} \mathrm{CO}_{2}$ caused by ICT directly.

Laitner et al. [17] conducted a study based on historical macroeconomic time series data about the U.S. economy before and after the introduction of the semiconductor. They concluded that in 2006, semiconductor technologies avoided $20 \%$ of total electricity consumption in the U.S. economy through productivity gains, compared to a baseline scenario without new investments in semiconductor technology. By using aggregated data on the whole U.S. economy, they implicitly consider all application domains and use cases of ICT as well as the electricity consumption of ICT hardware (direct effect).

Malmodin and Bergmark assess the global GHG abatement potential of ICT in 2030 through making grids, buildings, transport, work, travel, services and agriculture smart. They find that ICT has the potential to avoid between $8 \%$ and $15 \%$ of global GHG emissions in 2030 [18].

Assessments of indirect environmental effects of ICT also found their way into business practice. GeSI published a series of studies (SMART 2020, SMARTer 2020 and SMARTer 2030), in which they compared global direct and indirect impacts of ICT on GHG emissions [6], [19], [20]. The latest report, SMARTer 2030, explicitly considers ICT's impact on mobility, manufacturing, agriculture, buildings and energy. It estimates the global GHG abatement potential through ICT application to be 9.7 times larger than the direct GHG footprint of ICT (9.7 is called the "enablement factor"). Comparing the results 
of their studies shows that the GHG footprint (direct effect) of the ICT sector tends to decrease, while the GHG abatement potential through ICT seems to increase between 2020 and 2030.

In 2016, Accenture Strategy, who also supported GeSI in the SMARTer 2030 study, transferred the assessment of indirect effects of ICT of the SMARTer 2030 study to Switzerland. They concluded that, by 2030, ICT has the potential to avoid $18.4 \mathrm{Mt} \mathrm{CO}_{2} \mathrm{e}$ in Switzerland, not considering rebound effects (for comparison: the total domestic GHG emissions in Switzerland amounted to $48.1 \mathrm{Mt} \mathrm{CO}_{2} \mathrm{e}$ in 2015 [21]).

Similar to GeSI and Accenture, many TNOs estimated GHG enablement factors of their products and services. To do so, they compare the GHG emissions of the activities performed by their customers before and after the application of each ICT product. They then put the aggregated difference into relation to the GHG footprint of their operations (GHG Protocol Scope 1-32) and declare the result to be their GHG enablement factor. Table 1 provides an overview of the GHG enablement factors of different TNOs.

\begin{tabular}{|l|l|l|}
\hline TNO name & Latest GHG enablement factor (year; unit) & Target GHG enablement factor (year; unit) \\
\hline AT\&T $(\mathrm{US})$ & no current factor & $10: 1\left(2025 ; \mathrm{CO}_{2}\right)$ \\
\hline British Telecom $(\mathrm{GB})$ & $1.8: 1\left(2016 / 2017 ; \mathrm{CO}_{2} \mathrm{e}\right)$ & $3: 1\left(2017 / 2018 ; \mathrm{CO}_{2} \mathrm{e}\right)$ \\
\hline China Mobile $(\mathrm{CN})$ & $6.45: 1\left(2008 ; \mathrm{CO}_{2}\right)$ & $10: 1\left(2020 ; \mathrm{CO}_{2}\right)$ \\
\hline Deutsche Telekom (DE) & $1.33: 1\left(2016 ; \mathrm{CO}_{2}\right)$ & no target \\
\hline NTT (JP) & $12: 1(2016)$ & $10: 1\left(2031 ; \mathrm{CO}_{2}\right)$ \\
\hline Swisscom $(\mathrm{CH})$ & $0.99\left(2016 ; \mathrm{CO}_{2} \mathrm{e}\right)$ & $2: 1\left(2020 ; \mathrm{CO}_{2} \mathrm{e}\right)$ \\
\hline Verizon (US) & $0.98-1.44: 1\left(2015 ; \mathrm{CO}_{2} \mathrm{e} ;\right.$ without Scope $\left.3^{2}\right)$ & no target \\
\hline Vodafone (GB) & $1.9: 1\left(2016 / 2017 ; \mathrm{CO}_{2} \mathrm{e}\right)$ & no target \\
\hline
\end{tabular}

Table 1: Overview of current and target GHG enablement factors of different TNOs according to their external reporting [7]-[9], [22]-[27].

The outcomes of the overarching studies by Hilty et. al., Laitner, WWF, and GeSI, although not directly comparable due to different geographic and temporal scopes, yield varying net effects of ICT. Furthermore, if we compare the GHG enablement factors of different TNOs (Tab. 1), we can see - despite similarities in the underlying business models - that the enablement factors differ considerably. It is therefore important to identify the reasons behind this variety of results.

Without deeper analysis, we cannot claim that such studies provide a useful and reliable source of information for decision makers, enabling them to consider the (expected) environmental effect of an ICT application as a decision criterion. This is especially problematic as many businesses actively integrate this type of assessments into their marketing strategies, which in turn influences the decisionmaking of their customers.

To get some insight into the critical aspects of the methodology of such studies, we conducted a case study in which we reviewed the Accenture study for Switzerland and reconstructed it on the grounds of more precautionary assumptions. We dealt with the inherent uncertainty by not providing one forecast, but instead a set of three scenarios which differ in the assumptions taken about the development of the adoption and impact of the use cases analyzed.

${ }^{2}$ The GHG Protocol Scope 1-3 standard provides reporting guidelines for GHG emissions caused by a company's own assets, their demand for energy e.g. electricity and activities outside in their upstream and downstream value chain e.g. procured goods. 


\section{Method}

The goal of our case study was to estimate ICT's GHG abatement potential in Switzerland in 2030 by revisiting the study conducted by Accenture. The abatement potential quantifies the GHG emissions ICT can avoid in one year. We first analyzed the methodological approach taken by Accenture and then identified and re-evaluated - based on existing literature - the main assumptions. Finally, we defined three scenarios and recalculated the GHG abatement potential for each scenario.

In their study, Accenture transferred the results of the global GHG abatement potential of ICT in 2030, as identified in GeSI's SMARTer 2030 report, to the specific situation in Switzerland. SMARTer 2030 is based on twelve ICT use cases (such as "E-Health") and estimates the GHG abatement potential for each use case for ten focus countries (not including Switzerland), clusters the focus countries in four groups with macroeconomic similarities (GDP per capita, $\mathrm{CO}_{2} \mathrm{e}$ emissions per capita, number of internet users, and energy use) and extrapolates the focus country results to global figures using use-case-specific macroeconomic data (e.g., healthcare expenditure for the use case "E-Health"). The GHG abatement potential per use case (see Fig. 1) is estimated by

- identifying GHG abatement levers (e.g., reduction in transport demand or reduction in facilities needed),

- estimating baseline emissions, i.e., the prospective emissions caused in 2030 with current patterns before the use case was realized (e.g. extent of travel to hospitals before significant "E-Health" adoption),

- estimating the level of adoption of the use case in 2030, i.e., the share of the population that will use this ICT solution (e.g., the number of patients or hospitals adopting "EHealth"),

- estimating the impact on GHG emissions per unit of adoption of the ICT application (e.g., GHG emissions saved by the expected reduction in physical patient attendances in hospitals using "E-Health"),

- estimating the expected rebound effect (increase in demand due to higher efficiency [28]).

Out of the twelve ICT use cases in the SMARTer 2030 report, Accenture transferred ten to Switzerland ("Smart Agriculture" and "Smart Manufacturing" were excluded). Accenture did not disclose how they transferred the results per use case to Switzerland. In our analysis, we revisited the assumptions taken at the global level and adapted them to the situation in Switzerland - specifically the values for adoption, impacts and expected rebound effects - to recalculate an adapted GHG abatement potential for each use case. Additionally, we excluded ICT use cases if ICT was only a minor contributor to their realization and it did not seem justified to allocate a major part of the GHG abatement potential to ICT.

Our case study is based on the idea of scenario modelling: Since we assume that the future can be influenced by the actions taken today, we refrain from making a forecast and provide a set of possible futures (scenarios) instead. The scenarios span the space in which the outcome can be influenced by directed actions, actions which increase either the adoption levels or the impacts (in terms of GHG reductions) of a use case. To summarize, we revised the existing Accenture study by reassessing underlying assumptions, excluding use cases with minor ICT contribution, introducing scenario modelling and by discussing the methodological challenges in this kind of studies. 


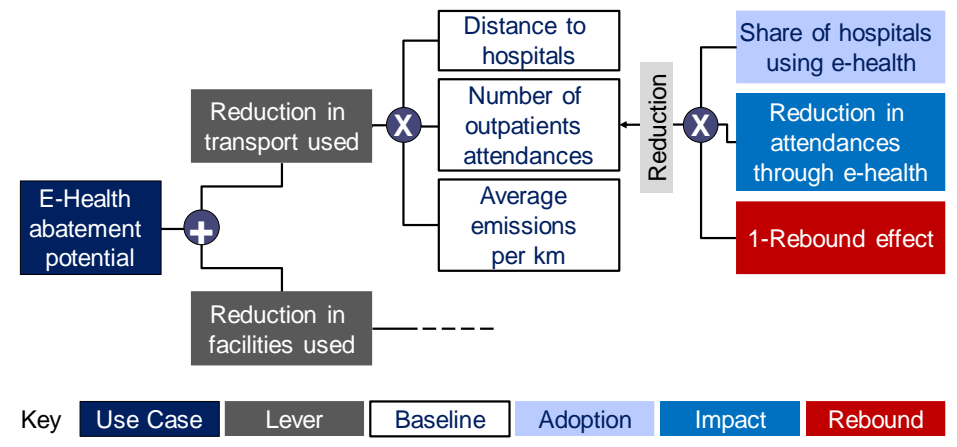

Figure 1: Calculation method based on SMARTer 2030 report at the example of "E-Health" (based on [6]). Rebound effects diminish the GHG reduction potential resulting from adoption and impact.

A description of the scenarios is provided in Tab. 2. For detailed information on the assumptions, please refer to the technical report [3] and its supplementary information, which can be requested from the authors. Please note that the technical report, in contrast to this paper, uses a time horizon until 2025 for contractual reasons.

\begin{tabular}{|l|l|}
\hline Scenario & Description \\
\hline Pessimistic & $\begin{array}{l}\text { The "Pessimistic" scenario combines (for each use case) } \\
- \text { an adoption level assuming that no directed actions to increase penetration of the use case are taken with } \\
- \text { the lower boundary of the data points for the impact identified in latest research. }\end{array}$ \\
\hline Expected & $\begin{array}{l}\text { The "Expected" scenario combines (for each use case) } \\
- \text { an adoption level that can be expected according to measures currently implemented or planned (business } \\
\text { as usual) with } \\
- \text { the average of the data points for the impact identified in latest research. }\end{array}$ \\
\hline Optimistic & $\begin{array}{l}\text { The "Optimistic" scenario combines (for each use case) } \\
- \text { an adoption level assuming that actions accelerating penetration of the use case are taken with } \\
- \text { the upper boundary of the data points for the impact identified in latest research. }\end{array}$ \\
\hline
\end{tabular}

Table 2: Scenarios used for the estimation of indirect effects.

\section{Results}

\subsection{Total GHG abatement potential in Switzerland}

Based on current expectations about the future development of the technology and its adoption, the potential for annual abatement will reach $3.98 \mathrm{Mt} \mathrm{CO}_{2} \mathrm{e}$ in 2030. In the "Optimistic" scenario, the abatement potential can even increase to $11.32 \mathrm{Mt} \mathrm{CO}_{2} \mathrm{e}$. However, in the "Pessimistic" scenario (no directed actions supporting adoption, lowest plausible impact of technology on GHG reduction), the abatement potential will only reach $1.00 \mathrm{Mt} \mathrm{CO}_{2} \mathrm{e}$. Replacing the adoption levels in 2030 with the adoption levels of 2015 yields $1.11 \mathrm{Mt} \mathrm{CO}_{2} \mathrm{e}$ abatement potential for the "Expected" scenario, showing that decision-makers can still influence the GHG abatement potential that will be reached in 2030 with targeted actions (see Fig. 2). 


\subsection{GHG abatement potential per use case}

Abatement potential varies significantly across use cases. The largest potentials lie in application domains that are both energy-intensive and provide products or services continuously required by the whole society. This is true for the buildings, transportation and the energy sector which turned out to bear significant ICT-enabled GHG reduction potentials. Sectors, such as health or banking provide less GHG emission abatement potential in absolute terms (see Fig. 3) mainly because their share of GHG emissions is small.

The abatement potential of each use case is an aggregation of the reduction potentials of the levers identified in this use case (see Fig. 1). The GHG abatement potential usually varies across levers. For example, for the use case "Traffic Control and Optimization", the optimization of vehicle routes provides more GHG emission abatement potential than the contribution of ICT to a change of the modal split towards public transport. This may be specific for Switzerland and other countries where the share of public transport is already very high. Therefore, increasing the adoption of use cases is not always favorable, as their impact is context-dependent and must be evaluated in each individual scenario. Table 3 summarizes the most relevant levers per use case.

\subsection{Our results compared to Accenture results}

Compared to the study of Accenture Strategy, the GHG abatement potential we estimated in the "Expected" scenario was lower for all use cases (see Fig. 4). Even in our "Optimistic" scenario, we estimated a lower GHG abatement potential for eight out of ten use cases. The results differ mainly because, on average, we estimated a significantly lower adoption in 2030 than Accenture Strategy and we were more conservative in allocating levers to ICT. In addition, we also estimated lower impacts and higher rebound effects on average than Accenture Strategy.

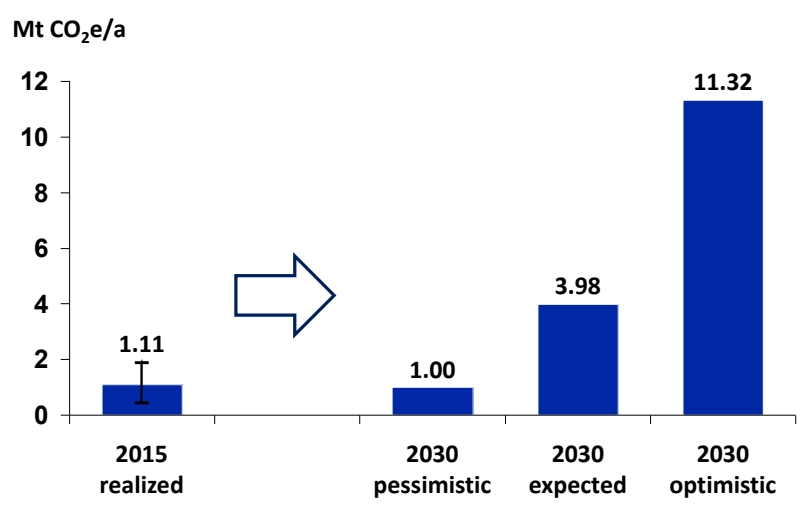

Figure 2: Realized abatement in 2015 and abatement potential in 2030 by scenario. The uncertainty in 2015 is due to uncertainty about the environmental impact of ICT in literature. 


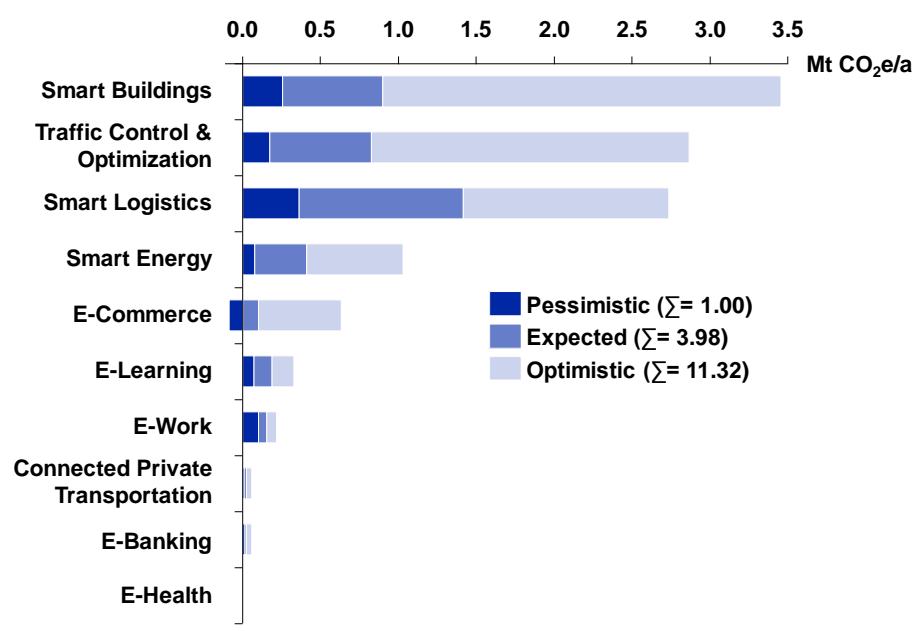

Figure 3: GHG abatement potential in 2030 in the "Pessimistic", "Expected" and "Optimistic" scenario by use case.

\subsection{Net effect of ICT on GHG emissions in Switzerland}

If we assume that direct effects of the ICT sector in Switzerland will amount to roughly $2.50 \mathrm{Mt}$ $\mathrm{CO}_{2} \mathrm{e}$ in 2030 (extrapolated from [3]), this would equal 63\% of the expected abatement potential in 2030 and correspond to an enablement factor of 1.59. If decision-makers manage to systematically explore ICT-related reduction potentials, we can expect an enablement factor of 4.53 ("Optimistic" scenario). However, if actions to increase the GHG abatement potential until 2030 are omitted, the ICT use cases can only avoid $40 \%$ of the footprint of the ICT sector in 2030 ("Pessimistic" scenario enablement factor 0.40). The net effect of ICT on GHG emissions can be increased further if actions to minimize the footprint of the ICT sector are taken [3]. More comprehensive life cycle assessment studies of ICT devices have shown that impact categories beyond global warming potential also matter (e.g. resource depletion, particulate matter, photo-oxidant creation potential, acidification potential and eutrophication of fresh water). However, the present study focuses on ICT's impact on GHG emissions.

\begin{tabular}{|l|l|}
\hline Use case & GHG abatement lever \\
\hline Smart Buildings & Building management systems reduce energy consumption of buildings \\
\hline Traffic Control \& Optimization & ICT enabled route optimization reduces transportation distances \\
\hline Smart Logistics & $\begin{array}{l}\text { Sharing of logistic assets increases utilization of existing logistic assets and reduces } \\
\text { transportation distances }\end{array}$ \\
\hline Smart Energy & Smart metering reduces energy consumption in households \\
\hline E-Commerce & $\begin{array}{l}\text { E-commerce avoids shopping related transportation but increases transportation for } \\
\text { distribution of goods }\end{array}$ \\
\hline E-Learning & E-learning avoids learning related transportation \\
\hline E-Work & E-work avoids work related transportation \\
\hline Connected Private Transportation & Car and ride sharing reduces transportation with private vehicles \\
\hline E-Banking & E-banking avoids banking related transportation \\
\hline E-Health & E-health avoids health related patient transportation \\
\hline
\end{tabular}

Table 3: Description of main lever of GHG abatement potential in 2030 by use case. 


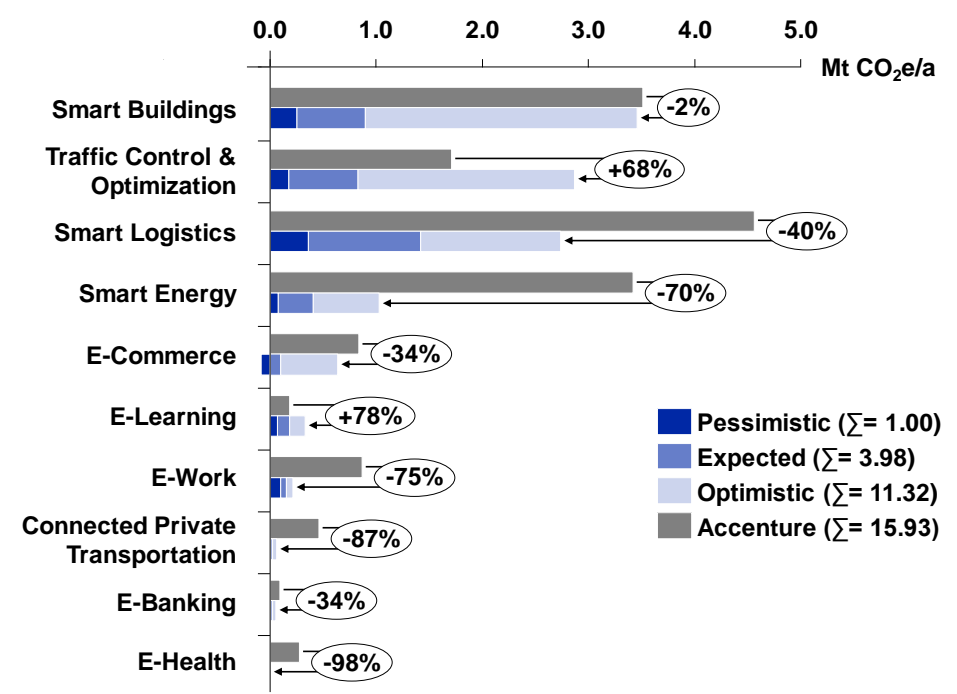

Figure 4: GHG abatement potentials in 2030 in the Accenture study and in our study by scenario. The percentages in brackets show the relative difference between Accenture results and our optimistic scenario.

\section{Discussion}

In the following discussion we focus on the assumptions we reassessed in our case study as well as further methodological challenges which influenced the Accenture study results and thereby also our own results. The methodological challenges we identify seem to be of general importance for the assessment of indirect environmental effects of ICT (some are also described in [29], [30]).

\subsection{Selection of use cases}

GeSI conducted the SMARTer 2030 report to research "the role Information and Communications Technology [...] can play in cutting global $\mathrm{CO}_{2} \mathrm{e}$ emissions" [6, p. 8]. Accordingly, the study focused on ICT use cases with the potential for optimization or substitution effects (as described by Hilty and Aebischer [31]) and thereby avoid GHG emissions. Use cases with induction effects (e.g., printers inducing the use of paper) or obsolescence effects (e.g., software updates make devices obsolete) were not in scope (except for "E-Commerce"). Systematically identifying such cases and including these in the study probably could have reduced the total GHG abatement potential. Defining the set of use cases is a general problem in the assessment of the overarching indirect effect of ICT on GHG emissions, since it is in principle impossible to analyze "all" future ICT applications that are potentially relevant. This caveat also applies to our own study, as we cannot exclude the possibility that a disruptive application will change the situation more fundamentally than our projections can assume. This may include even better prospects for GHG abatement (some ideas are formulated in Hilty [32]).

\subsection{Allocation}

GeSI and Accenture analyzed use cases which involve some sort of ICT application. However, the significance of the ICT application as an enabler of the use case varies a lot across use cases. For example, in the SMARTer 2030 report, GeSI identified $1.77 \mathrm{GT} \mathrm{CO}_{2}$ e global GHG abatement potential due to the increase in renewable energies. Although the substitution of renewable for fossil energy sources will 
probably not be possible without the help of ICT, many other technologies are required as well. It is therefore debatable whether the GHG reduction due to this substitution can be allocated fully to ICT applications. In contrast, for the realization of intelligent heating, ICT can be considered the main enabler. As the examples show, the assessment of ICT-induced GHG savings raises allocation issues as "ICT typically does not induce efficiency on its own, but only in a suitable technological, political or organizational context" [33, p. 2]. Especially for studies comparing the footprint of the ICT sector with its GHG abatement potential, there is no obvious way for allocating the abatement potential among ICT and other technologies required for its realization. Overestimating the net reducing effect of ICT on GHG emissions by applying a " $100 \%$ for ICT" allocation rule (thus glorifying ICT's contribution to climate protection) can nourish the illusion that digitalization will save the climate without substantial action of stakeholders. However, there is no objective solution to this sort of allocation problem and this kind of discussion can be questioned as "important [...] is certainly the carbon abatement, not whether it is ICT's exclusive merit" [34, p. 58].

\subsection{Baseline}

Assessments of indirect effects of ICT on GHG emissions need to identify baseline emissions, i.e., the emissions that would be expected if the ICT use case under study were not adopted [29]. Isolating the adoption of specific ICT use cases from a baseline scenario can be difficult since ICT has widely penetrated society. To estimate an indirect effect of ICT, would we seriously try to define the baseline as a scenario "without" ICT? It is difficult to imagine how a world without ICT would look like. For example, if no Internet existed, our patterns of communication, our lifestyles and ways of making business most probably would have developed in a different way. This problem is even larger for prospective studies, since "the baseline scenario, [...] as it expands into the future, is inherently speculative" [33, p. 138].

Often, researchers choose a baseline provided by a recognized third party, such as the Intergovernmental Panel on Climate Change (IPCC). In such cases, to avoid double counting, one has to analyze the developments considered in the baseline scenario and ensure that they do not overlap with the use cases under study.

\subsection{Impact}

In our study, we estimated the actual impact of the use case levers on baseline GHG emissions (e.g., to what extent smart meters reduce household energy consumption). However, estimating the actual impact is tricky because ICT's "theoretical potentials materialize only under specific conditions" [29, p. 1]. For example, in a city with convenient public transportation, a car sharing system might replace public transport trips, whereas in rural areas, it might rather replace private car trips. The impact on GHG emissions will be very different depending on such contextual factors. Even explicit research on specific environmental impacts of ICT applications struggles to quantify the impact. Malmodin and Coroama [35] find an invert correlation between the sample size and the energy reduction potential in studies about the energy consumption reduction impact of smart meters. Among the reasons for these difficulties are ICT's "exceptional dynamics of innovation and diffusion", its "social embedment and cross-sector application", its "diverse and complex impact patterns" [36, p. 1] and the complexity of social and ecological systems, which makes it hard to isolate the impact of ICT and predict the outcome of an ICT application [37].

Due to these complex impact patterns, defining the system boundary is also challenging. An ICT application can have clearly recognizable consequences (e.g. reducing the fuel use of a combustion engine), but also hidden consequences, such as long-term rebound effects and other structural effects (e.g., how do social practices change in the long-run). In this study we tried to account for the uncertain impact by applying scenario technique, as suggested by Erdmann and Hilty [36]. In our expected scenario, 
we estimated on average a lower impact than Accenture, contributing to a lower GHG abatement potential.

\subsection{Adoption}

In our study, we had to estimate the future adoption of all ICT use cases in 2030. Future estimations always involve uncertainty, especially for ICT use cases due to ICT's "exceptional dynamics of innovation and diffusion" [36, p. 1]. In their studies, GeSI and Accenture often use the Gartner Hype Cycle, which provides "a graphic representation of the maturity and adoption of technologies and applications" [38, p. 1]. Using the "Hype Cycle" can be dangerous because, first, it classifies technologies and not use cases, and second, its classification dimensions (expectation of society and time on the market) do not necessarily reflect actual adoption.

The main issue we faced was a lack of forecast data (e.g., generated with technology diffusion models) for the adoption of the use cases. Where no forecasts were available, we had to rely on data from countries comparable to Switzerland or select proxy indicators. A strategy to deal with uncertainty is the collection of data from various relevant proxy indicators and, if available, also expert opinions to take an informed assumption. In case there are diverging opinions or forecasts, they can be assigned to different scenarios to make the uncertainty transparent. In our "Expected" scenario, we estimated on average a lower adoption than Accenture, contributing to a lower GHG abatement potential.

\subsection{Rebound effect}

Rebound effects are known to play an important role in ICT applications [39]. As stated by Gossart, "ICT are subject to important rebound effects of all kinds (energy, time, knowledge-related) [...] because ICT are general purpose technologies that can generate high resource savings throughout the entire economy and society" [28, p. 445]. We included rebound effects in our calculations, however, we are aware of the high uncertainty in estimating rebound effects. From an economic point of view, rebound effects are based on demand elasticities, which are difficult to predict, especially in the long term. Observed elasticities are marginal values, therefore only valid for current absolute values. Additionally, ICT is a driver of GDP growth, which usually increases GHG emissions. However, the general discussion about growth and decoupling of GDP from resource flow - although a crucial issue - cannot be covered by this paper, since it is not specific for ICT.

In our study and in the Accenture study, rebound effects are represented as one relative reduction of the GHG abatement potential. Thereby, it is unclear how direct and indirect rebound effects shall be combined, as the method does not provide any guidance how to do so. For example, for "E-Health", consuming health services becomes more convenient and patients save time and money. A direct rebound effect would lead to increased use of healthcare services, whereas an indirect rebound effect would lead to increased consumption of other products and services with the time and money saved on health services.

In our study, we conducted a literature review to identify the most relevant rebound effects for the specific use cases, however, also struggled with lack of relevant data for all use cases. On average, we estimated higher rebound effects than Accenture, leading to a lower GHG abatement potential

\subsection{Interaction}

In studies analyzing several use cases individually to sum up their GHG abatement potentials, interaction between use cases may be an issue. Our study, as the Accenture study, analyzes ten use cases individually and mostly treats them as separate systems. However, interaction between use cases is plausible. First, abatement potentials of one use case (e.g. avoided travel due to "E-Health") may affect abatement potentials of other use cases (e.g., fuel saved through route optimization by "Traffic Control 
and Optimization"). GeSI and Accenture state that they account for such interactions. Secondly, there may be more complex systemic effects of use cases. Selected use cases may fundamentally change our patterns of production and consumption, leading to immediate or remote impacts on other use cases. For example, "E-Work" may fundamentally change commuting habits, which not only has influence on mobility patterns, but also our shopping behavior in the long run. For analyzing such effects, dynamic modelling and simulation techniques are required.

\subsection{Extrapolation}

GeSI and Accenture provide the macroeconomic indicators used for extrapolating the use case results to the global scale. However, the detailed calculation is not transparent. Malmodin and Coroama warn against extrapolating results from case studies that may not be representative [35].

\section{Conclusion}

ICT is an important enabler for a low-carbon economy in Switzerland. Regarding GHG abatement, there is an unprecedented opportunity and a resulting social responsibility for the ICT sector to take ambitious and targeted actions to enable other sectors to implement ICT-based ("smart") low-carbon solutions, both in terms of technologies and business models. This can mainly be done by further developing smart solutions in buildings, traffic control and optimization, logistics, and energy.

However, ICT-based solutions can only unleash its GHG reduction potential if targeted actions are taken. If no actions are taken and expected impacts cannot be realized, ICT will not contribute to climate protection in Switzerland. Rebound effects (increasing demands due to lower cost), compensating for the abatement, pose an additional risk.

Our study showed that, in absolute terms, ICT could enable the Swiss economy to save up to 11.32 $\mathrm{Mt} \mathrm{CO}_{2} \mathrm{e}$ per year (optimistic scenario). However, this figure has to be interpreted with care as assessments of indirect environmental effects of ICT face several methodological challenges, mainly implied by the complex, cross-sector impact patterns of ICT. How a study deals with these challenges has a crucial influence on the result. In our study, we reassessed the adoption levels, the impact, allocation and rebound effects of an existing study by Accenture and thereby reduced the identified GHG abatement potential already by roughly $29 \%$ ("Optimistic" scenario).

By analyzing related studies and reflecting on our own study, we identified the following methodological challenges for studies assessing indirect ICT impacts: the selection of the use cases, allocation problems regarding the contribution of ICT among several involved technologies, the definition of the baseline to measure relative impacts, contextual factors influencing the impact of a given use case, the inherent uncertainty in predicting adoption, estimating rebound effects of different types, potential interaction among use cases, and the necessity to extrapolate from case studies that may not be sufficiently representative.

We suggest the development of recommendations addressing these methodological challenges to improve the comparability and significance of the results and provide decision makers with more reliable information on the GHG abatement potential of ICT. Studies assessing the indirect effect of ICT on GHG emissions should explicitly consider the methodological challenges described in paragraph 5 and transparently discuss their approach to addressing these challenges. Also, uncertainty should be explicitly addressed, especially with regard to rebound effects. 


\section{Acknowledgement}

The authors would like to thank Res Witschi, Marius Schlegel and Mischa Kaspar from Swisscom Corporate Responsibility, as well as Sabine Loetscher and Nico Frey from WWF Switzerland for their collaboration in the case study on Switzerland.

\section{References}

[1] United Nations, "Sustainable Development Goals," 2017. Available: http://www.un.org/sustainabledevelop ment/ sustainable-development-goals/. [Accessed: 07-Nov-2017].

[2] UNFCCC, "Paris Agreement," 2015, p. 16.

[3] L. M. Hilty and J. C. T. Bieser, "Opportunities and Risks of Digitalization for Climate Protection in Switzerland," University of Zurich, Zurich, 2017.

[4] S. Brennen and D. Kreiss, "Digitalization and Digitization," Culture Digitally, 2014. Available: http:// culturedigitally.org/20 14/09/digitalization-and-digitization/. [Accessed: 18-Sep-2017].

[5] D. Pamlin and K. Szomolányi, "Saving the climate @ the speed of light. First roadmap for reduced CO2 emissions in the EU and beyond," European Telecommunications Network Operators' Association, WWF, 2006.

[6] GeSI, “\#SMARTer2030. ICT Solutions for 21st Century Challenges,” Brüssel, 2015.

[7] BT Group Plc, “Key Performance Indicators 2016/2017,” British Telecom, 2017.

[8] Swisscom AG, "Nachhaltigkeitsbericht 2016," Swisscom, 2017.

[9] AT\&T Inc, “Connect to Good. A Roadmap to 2025," AT\&T, 2017.

[10] M. Ahmadi Achachlouei and L. M. Hilty, "Modeling the Effects of ICT on Environmental Sustainability: Revisiting a System Dynamics Model Developed for the European Commission," in ICT Innovations for Sustainability, Springer, Cham, 2015, pp. 449-474.

[11] L. M. Hilty, P. Arnfalk, L. Erdmann, J. Goodman, M. Lehmann, and P. A. Wäger, "The relevance of information and communication technologies for environmental sustainability - A prospective simulation study,” Environ. Model. Softw., vol. 21, no. 11, pp. 1618-1629, 2006.

[12] Accenture Strategy, “\#SMARTer2030 follow up: Business Case Analysis for Swisscom,” 2016.

[13] Å. Moberg, C. Borggren, and G. Finnveden, "Books from an environmental perspective-Part 2: e-books as an alternative to paper books," Int. J. Life Cycle Assess., vol. 16, no. 3, pp. 238-246, Mar. 2011.

[14] V. C. Coroama, L. M. Hilty, and M. Birtel, "Effects of Internet-based multiple-site conferences on greenhouse gas emissions,” Telemat. Inform., vol. 29, no. 4, pp. 362-374, Nov. 2012.

[15] C. L. Weber, J. G. Koomey, and H. S. Matthews, "The Energy and Climate Change Implications of Different Music Delivery Methods,” J. Ind. Ecol., vol. 14, no. 5, pp. 754-769, Oct. 2010.

[16] D. Pamlin, "From fossil to future with innovative ICT solutions. Increased CO2 emissions from ICT needed to save the climate," WWF, Barcelona, 2008.

[17] J. A. "Skip" Laitner, C. P. Knight, V. L. McKinney, and K. Ehrhardt-Martinez, "Semiconductor technologies: The potential to revolutionize U.S. energy productivity (Part III)," Environ. Qual. Manag., vol. 19, no. 4, pp. 29-50, Jun. 2010.

[18] J. Malmodin and P. Bergmark, "Exploring the effect of ICT solutions on GHG emissions in 2030," in Proceedings of EnviroInfo and ICT for Sustainability 2015, Copenhagen, Denmark, 2015, pp. 37-46.

[19] The Climate Group and GeSI, "SMART 2020. Enabling the low carbon economy in the information age," GeSI, The Climate Group, 2008.

[20] GeSI and The Boston Consulting Group, "SMARTer 2020: The Role of ICT in Driving a Sustainable Future.," GeSI, The Boston Consulting Group, 2012.

[21] FOEN, "Greenhouse gas inventory," Greenhouse gas inventory, 2017. Available: https://www.bafu.admin. ch/bafu/en/home/topics/climate/state/data/greenhouse-gas-inventory.html. [Accessed: 06-Sep-2017]. 
[22] China Mobile Ltd, "Big Connectivity, New Future: 2016 Sustainability Report,” 2016.

[23] Y. Tianjian, H. Yiwen, Z. Ping, and D. Pamlin, "Low Carbon Telecommunication Solutions in China: Current Reductions and Future Potential," 2010.

[24] Deutsche Telekom AG, “Corporate Responsibility Report 2016,” Bonn, 2017.

[25] NTT Group, “NTT Group Sustainability Report 2016,” 2016.

[26] Verizon, “A better future for everyone. 2016 Corporate Responsibility Supplement,” 2017.

[27] Vodafone Group Plc, "Sustainable Business Report 2015-16," 2016.

[28] C. Gossart, "Rebound Effects and ICT: A Review of the Literature," in ICT Innovations for Sustainability, Springer, Cham, 2015, pp. 435-448.

[29] L. M. Hilty, B. Aebischer, and A. E. Rizzoli, "Modeling and evaluating the sustainability of smart solutions," Environ. Model. Softw., vol. 56, pp. 1-5, Jun. 2014.

[30] J. Malmodin, P. Bergmark, N. Lövehagen, M. Ercan, and A. Bondesson, "Considerations for macro-level studies of ICT's enablement potential," in Proceedings of ICT for Sustainability 2014, Stockholm, Sweden, 2014, pp. 179-188.

[31] L. M. Hilty and B. Aebischer, "ICT for Sustainability: An Emerging Research Field," in ICT Innovations for Sustainability, L. M. Hilty and B. Aebischer, Eds. Springer International Publishing, 2015, pp. 3-36.

[32] L. M. Hilty, "Computing Efficiency, Sufficiency, and Self-sufficiency: A Model for Sustainability?," in LIMITS 2015, First Workshop on Computing within Limits, 2015, pp. 15-16.

[33] V. C. Coroama, D. Schien, C. Preist, and L. M. Hilty, "The Energy Intensity of the Internet: Home and Access Networks," in ICT Innovations for Sustainability, Springer, Cham, 2015, pp. 137-155.

[34] V. C. Coroama, "The enablement potential of ICT: Enabling what? How? Why?," presented at the ICT4S Summer School 2017, Leiden, Netherlands, 01-Aug-2017.

[35] J. Malmodin and V. C. Coroama, “Assessing ICT's enabling effect through case study extrapolation. The example of smart metering," in 2016 Electronics Goes Green 2016+ (EGG), 2016, pp. 1-9.

[36] L. Erdmann and L. M. Hilty, "Scenario Analysis: Exploring the Macroeconomic Impacts of Information and Communication Technologies on Greenhouse Gas Emissions," J. Ind. Ecol., vol. 14, no. 5, pp. 826-834, 2010.

[37] M. Börjesson Rivera, C. Håkansson, A. Svenfelt, and G. Finnveden, "Including second order effects in environmental assessments of ICT," Environ. Model. Softw., vol. 56, pp. 105-115, 2014.

[38] Gartner Inc, "Hype Cycle Research Methodology | Gartner Inc.," Research Methodologies, 2017. Available: https://www.gartner.com/technology/research/methodologies/hype-cycle.jsp. [Accessed: 02-Nov-2017].

[39] L. M. Hilty, "Emerging Risks in Information Infrastructures: A Technology Assessment Perspective," Proc. IDRC 2008 Int. Disaster Risk Conf., 2008. 